\title{
Closed Neighborhood Degree Sum-Based Topological Descriptors of Graphene Structures
}

\author{
Vignesh Ravi ${ }^{1}$ (D), Kalyani Desikan ${ }^{1, *}$ (i) \\ 1 Division of Mathematics, School of Advanced Sciences, Vellore Institute of Technology, Chennai; \\ rvignesh.2018@vitstudent.ac.in (V.R.), kalyanidesikan@vit.ac.in (K.D.); \\ 2 Correspondence: kalyanidesikan@vit.ac.in (K.D);
}

Scopus Author ID 7005615253

Received: 29.09.2021; Revised: 1.11.2021; Accepted: 5.11.2021; Published: 21.11.2021

\begin{abstract}
Topological descriptors defined on chemical structures enable understanding the properties and activities of chemical molecules. In this paper, we compute closed neighborhood degree sum-based indices for four different Graphene structures. The cardinality of closed neighborhood degree-based edge partitions for four different Graphene structures is used to compute the closed neighborhood degree sum-based indices.
\end{abstract}

Keywords: Graphene structure; closed neighborhood degree; closed neighborhood degree-based topological indices; reciprocal indices.

(C) 2021 by the authors. This article is an open-access article distributed under the terms and conditions of the Creative Commons Attribution (CC BY) license (https://creativecommons.org/licenses/by/4.0/).

\section{Introduction}

Cheminformatics is a field of study that employs quantitative structure behavior and structure-property relationships to study chemical compounds' bioactivities and properties [1, 2]. In research findings, physicochemical properties and topological indices are used to predict the bioactivity of organic compounds [3]. Nodes represent atoms or molecules in a chemical graph, while the links denote the chemical bond between the atoms or molecules.

Topological descriptors defined on chemical structures play a crucial role in understanding the properties and activities of chemical molecules. The degree of a vertex is indicated by $d_{u}$ or $d(u)$ [4], and it denotes the number of edges that are incident on that vertex. The closed neighborhood degree of a node $u \in V$, indicated as $\delta[u]$, is the sum of degrees of all the nodes in the neighborhood of the node $u$ and $d(u)$.

Graphene, a carbon allotrope with a honeycomb grid structure, is the most enduring compound material. It has excellent thermal and electric conductivity properties. It has a high nonlinear magnetic property compared to graphite.

Numerous researchers have described and evaluated various topological descriptors of many compounds, such as Graphene, Graphene transformations, and their applications [5 - 34].

Open neighborhood degree sum-based topological indices were studied recently by Vignesh and Kalyani Desikan [35]. They proposed some new open neighborhood degree sum based indices, namely, $S K_{N}, S K 1_{N}, S K 2_{N}, m R_{N}, I S I_{N}$. Vignesh et al. [36] proposed the reciprocal versions of the indices mentioned in [35]. Further, Vignesh and Kalyani Desikan [37] proposed the closed neighborhood versions of the aforesaid topological indices denoted as $S K_{N}^{c}(\mathrm{G}), S K 1_{N}^{c}(\mathrm{G}), S K 2_{N}^{c}(\mathrm{G}), m R_{N}^{c}(\mathrm{G}), I S I_{N}^{c}(\mathrm{G})$ along with their reciprocal versions as follows: 


$$
\begin{aligned}
& S K_{N}^{c}(\mathrm{G})=\sum_{u v \in E(G)}\left[\frac{\delta[u]+\delta[v]}{2}\right] \\
& S K 1_{N}^{c}(G)=\sum_{u v \in E(G)}\left[\frac{\delta[u] * \delta[v]}{2}\right] \\
& S K 2_{N}^{c}(\mathrm{G})=\sum_{u v \in E(G)}\left[\frac{\delta[u]+\delta[v]}{2}\right]^{2} \\
& m R_{N}^{c}(\mathrm{G})=\sum_{u v \in E(G)}\left[\frac{1}{\max \{\delta[u], \delta[v]\}}\right] \\
& I S I_{N}^{c}(\mathrm{G})=\sum_{u v \in E(G)}\left[\frac{\delta[u] * \delta[v]}{\delta[u]+\delta[v]}\right] \\
& R S K_{N}^{c}(\mathrm{G})=\sum_{u v \in E(G)}\left[\frac{2}{\delta[u]+\delta[v]}\right] \\
& R S K 1_{N}^{c}(G)=\sum_{u v \in E(G)}\left[\frac{2}{\delta[u] * \delta[v]}\right] \\
& R S K 2_{N}^{c}(\mathrm{G})=\sum_{u v \in E(G)}\left[\frac{2}{\delta[u]+\delta[v]}\right]^{2} \\
& R m R_{N}^{c}(\mathrm{G})=\sum_{u v \in E(G)}[\max \{\delta[u], \delta[v]\}] \\
& R I S I_{N}^{c}(\mathrm{G})=\sum_{u v \in E(G)}\left[\frac{\delta[u]+\delta[v]}{\delta[u] * \delta[v]}\right]
\end{aligned}
$$

where $\delta[u]=\left[\sum_{v \in N(u)} \operatorname{deg}(v)\right]+\operatorname{deg}(u), N(u)$ is the Neighborhood set of the vertex $u$.

In this paper, we estimate the closed neighborhood topological descriptors $S K_{N}^{c}(\mathrm{G})$, $S K 1_{N}^{c}(\mathrm{G}), S K 2_{N}^{c}(\mathrm{G}), m R_{N}^{c}(\mathrm{G}), I S I_{N}^{c}(\mathrm{G})$ as well as their reciprocal versions. The results are obtained by ascertaining the cardinality of edge partitions of the four distinct Graphene structures. For the Graphene structures, refer to [29].

Graphene structures can be classified into four based on the number of layers and benzene rings. The edge types for the four structures are indicated by $(\delta[\mathbf{u}], \delta[\mathbf{v}])$. The edge partitions for the four structures are presented in the tables below:

Table 1.'Edge Partition when a $>1 \mathrm{~b}>1$.

\begin{tabular}{c|c|c|c|c|c|c|c|c|c} 
Edge Type & $(6,7)$ & $(7,7)$ & $(7,10)$ & $(7,11)$ & $(8,10)$ & $(10,12)$ & $(11,11)$ & $(11,11)$ & $(12,12)$ \\
\hline Number of Edges & 4 & $\mathrm{a}$ & 8 & $2 \mathrm{a}-4$ & $4 \mathrm{~b}-8$ & $\boldsymbol{2 b}$ & $\mathrm{a}-2$ & $2 \mathrm{a}-4$ & $3 \mathrm{ab}-4 \mathrm{a}-4 \mathrm{~b}+5$
\end{tabular}

Table 2. 'Edge Partition when $\mathrm{a}=1 \mathrm{~b}>1$.

\begin{tabular}{c|c|c|c|c|c|c} 
Edge Type & $\mathrm{E}\left(\delta_{\mathrm{u}}, \delta_{\mathrm{v}}\right)$ & $(6,6)$ & $(6,7)$ & $(7,10)$ & $(8,10)$ & $(10,10)$ \\
\hline Number of Edges & $\mid{ }^{\prime} \mathrm{E}\left(\delta_{\mathrm{u}}, \delta_{\mathrm{v}}\right)$ & 2 & 4 & 4 & $4 \mathrm{~b}-8$ & $\mathrm{~b}-1$
\end{tabular}

Table 3. 'Edge Partition when a $>1 \mathrm{~b}=1$.

\begin{tabular}{c|c|c|c|c|c|c|c} 
Edge Type & $(6,6)$ & $(6,7)$ & $(7,7)$ & $(7,10)$ & $(7,11)$ & $(10,11)$ & $(11,11)$ \\
\hline Number of Edges & 2 & 4 & $\mathrm{a}-2$ & 4 & $2 \mathrm{a}-4$ & 2 & $2 \mathrm{a}-5$
\end{tabular}

Table 4. 'Edge Partition when $\mathrm{a}=1 \mathrm{~b}=1$.

\begin{tabular}{c|c} 
Edge Type & $(6,6)$ \\
\hline Number of Edges & 6
\end{tabular}

where $\boldsymbol{a}$ and $\boldsymbol{b}$ denote the rows and number of benzene rings, respectively. 


\section{Materials and Methods}

The closed neighborhood degree sum-based topological descriptors of Graphene structures have been computed. To obtain our results, we adopted the closed neighborhood degree sum-based edge partition method.

\section{Results on Closed Neighborhood Degree Based Topological Descriptors}

In this section, we compute closed neighborhood degree-based topological indices, namely, $S K_{N}^{c}, S K 1_{N}^{c}, S K 2_{N}^{c}, m R_{N}^{c}, I S I_{N}^{c}$, of Graphene structures.

Theorem 3.1: $S K_{N^{c}}$ index of Graphene with a rows and b benzene rings is given by

$$
S K_{N^{c}}=\left\{\begin{array}{lll}
11 a+10 b+36 a b-22 & \text { if } & a>1, b>1 \\
46 b-10 & \text { if } & a=1, b>1 \\
47 a-12 & \text { if } & a>1, b=1 \\
36 & \text { if } & a=1, b=1
\end{array}\right.
$$

Proof: We provide the proof for the four cases,

Case 1: From Table 1, we use the edge partition for $\mathrm{a}>1, \mathrm{~b}>1$ in equation 1 to obtain,

$$
\begin{aligned}
S K_{N^{c}} & =\sum_{u v \in E_{1}}\left[\frac{6+7}{2}\right]+\sum_{u v \in E_{2}}\left[\frac{7+7}{2}\right]+\sum_{u v \in E_{3}}\left[\frac{7+10}{2}\right]+\sum_{u v \in E_{4}}\left[\frac{7+11}{2}\right] \\
& +\sum_{u v \in E_{5}}\left[\frac{8+10}{2}\right]+\sum_{u v \in E_{6}}\left[\frac{10+12}{2}\right]+\sum_{u v \in E_{7}}\left[\frac{11+11}{2}\right]+\sum_{u v \in E_{8}}\left[\frac{11+12}{2}\right] \\
& +\sum_{u v \in E_{9}}\left[\frac{12+12}{2}\right] \\
= & 11 a+10 b+36 a b-22 .
\end{aligned}
$$

Case 2: From Table 2, we use the edge partition for $a=1, b>1$ in equation 1 to obtain,

$$
\begin{aligned}
& S K_{N^{c}}=\sum_{u v \in E_{1}} {\left[\frac{6+6}{2}\right]+\sum_{u v \in E_{2}}\left[\frac{6+7}{2}\right]+\sum_{u v \in E_{3}}\left[\frac{7+10}{2}\right]+\sum_{u v \in E_{4}}\left[\frac{8+10}{2}\right] } \\
&+\sum_{u v \in E_{5}}\left[\frac{10+10}{2}\right] \\
&=46 b-10 .
\end{aligned}
$$

Case 3: From Table 3, we use the edge partition for $\mathrm{a}>1, \mathrm{~b}=1$ in equation 1 to obtain,

$$
\begin{aligned}
S K_{N^{c}}= & \sum_{u v \in E_{1}}\left[\frac{6+6}{2}\right]+\sum_{u v \in E_{2}}\left[\frac{6+7}{2}\right]+\sum_{u v \in E_{3}}\left[\frac{7+7}{2}\right]+\sum_{u v \in E_{4}}\left[\frac{7+10}{2}\right]+\sum_{u v \in E_{5}}\left[\frac{7+11}{2}\right] \\
& +\sum_{u v \in E_{6}}\left[\frac{10+11}{2}\right]+\sum_{u v \in E_{7}}\left[\frac{11+11}{2}\right] \\
= & 47 a-12 .
\end{aligned}
$$


Case 4: From Table 4, we use the edge partition for $\mathrm{a}=1, \mathrm{~b}=1$ in equation 1 to obtain,

$$
S K_{N}^{\zeta}=\sum_{u v \in E_{1}}\left[\frac{6+6}{2}\right]=36 .
$$

Theorem 3.2: $S K 1_{N^{c}}$ index of Graphene with a rows and $b$ benzene rings is given by

$$
S K 1_{N^{c}}=\left\{\begin{array}{lll}
6 a-8 b+216 a b-135 & \text { if } & a>1, b>1 \\
210 b-110 & \text { if } & a=1, b>1 \\
\frac{445 a-271}{2} & \text { if } & a>1, b=1 \\
108 & \text { if } & a=1, b=1
\end{array}\right.
$$

Proof: We provide the proof for the four cases,

Case 1: From Table 1, we use the edge partition for $\mathrm{a}>1, \mathrm{~b}>1$ in equation 2 to obtain,

$$
\begin{aligned}
S K 1_{N^{c}}=\sum_{u v \in E_{1}} & {\left[\frac{6 * 7}{2}\right]+\sum_{u v \in E_{2}}\left[\frac{7 * 7}{2}\right]+\sum_{u v \in E_{3}}\left[\frac{7 * 10}{2}\right]+\sum_{u v \in E_{4}}\left[\frac{7 * 11}{2}\right]+\sum_{u v \in E_{5}}\left[\frac{8 * 10}{2}\right] } \\
& +\sum_{u v \in E_{6}}\left[\frac{10 * 12}{2}\right]+\sum_{u v \in E_{7}}\left[\frac{11 * 11}{2}\right]+\sum_{u v \in E_{8}}\left[\frac{11 * 12}{2}\right]+\sum_{u v \in E_{9}}\left[\frac{12 * 12}{2}\right] \\
= & 6 a-8 b+216 a b-135 .
\end{aligned}
$$

Case 2: From Table 2, we use the edge partition for $a=1, b>1$ in equation 2 to obtain,

$$
\begin{gathered}
S K 1_{N^{c}}=\sum_{u v \in E_{1}}\left[\frac{6 * 6}{2}\right]+\sum_{u v \in E_{2}}\left[\frac{6 * 7}{2}\right]+\sum_{u v \in E_{3}}\left[\frac{7 * 10}{2}\right]+\sum_{u v \in E_{4}}\left[\frac{8 * 10}{2}\right]+\sum_{u v \in E_{5}}\left[\frac{10 * 10}{2}\right] \\
=210 b-110 .
\end{gathered}
$$

Case 3: From Table 3, we use the edge partition for $\mathrm{a}>1, \mathrm{~b}=1$ in equation 2 to obtain,

$$
\begin{gathered}
S K 1_{N^{c}}=\sum_{u v \in E_{1}}\left[\frac{6 * 6}{2}\right]+\sum_{u v \in E_{2}}\left[\frac{6 * 7}{2}\right]+\sum_{u v \in E_{3}}\left[\frac{7 * 7}{2}\right]+\sum_{u v \in E_{4}}\left[\frac{7 * 10}{2}\right]+\sum_{u v \in E_{5}}\left[\frac{7 * 11}{2}\right] \\
+\sum_{u v \in E_{6}}\left[\frac{10 * 11}{2}\right]+\sum_{u v \in E_{7}}\left[\frac{11 * 11}{2}\right] \\
=\frac{445 a-271}{2} .
\end{gathered}
$$

Case 4: From Table 4, we use the edge partition for $\mathrm{a}=1, \mathrm{~b}=1$ in equation 2 to obtain,

$$
S K 1_{N^{c}}=\sum_{u v \in E_{1}}\left[\frac{6 * 6}{2}\right]=108 .
$$

Theorem 3.3: $S K 2{ }_{N^{c}}$ index of Graphene with a rows and $b$ benzene rings is given by 


$$
S K 2_{N^{c}}=\left\{\begin{array}{lll}
\frac{41 a-20 b+864 a b-552}{2} & \text { if } & a>1, b>1 \\
\frac{424 b-218}{906 a-553} & \text { if } & a=1, b>1 \\
216 & \text { if } & a>1, b=1 \\
\frac{90}{2} & \text { if } & a=1, b=1
\end{array}\right.
$$

Proof: We provide the proof for the four cases,

Case 1: From Table 1, we use the edge partition for $a>1, b>1$ in equation 3 to obtain,

$$
\begin{gathered}
S K 2_{N^{c}}=\sum_{u v \in E_{1}}\left[\frac{6+7}{2}\right]^{2}+\sum_{u v \in E_{2}}\left[\frac{7+7}{2}\right]^{2}+\sum_{u v \in E_{3}}\left[\frac{7+10}{2}\right]^{2}+\sum_{u v \in E_{4}}\left[\frac{7+11}{2}\right]^{2} \\
+\sum_{u v \in E_{5}}\left[\frac{8+10}{2}\right]^{2}+\sum_{u v \in E_{6}}\left[\frac{10+12}{2}\right]^{2}+\sum_{u v \in E_{7}}\left[\frac{11+11}{2}\right]^{2} \\
+\sum_{u v \in E_{8}}\left[\frac{11+12}{2}\right]^{2}+\sum_{u v \in E_{9}}\left[\frac{12+12}{2}\right]^{2} \\
=\frac{41 a-20 b+864 a b-552}{2} .
\end{gathered}
$$

Case 2: From Table 2, we use the edge partition for $\mathrm{a}=1, \mathrm{~b}>1$ in equation 3 to obtain,

$$
\begin{aligned}
S K 2_{N^{c}}= & \sum_{u v \in E_{1}}\left[\frac{6+6}{2}\right]^{2}+\sum_{u v \in E_{2}}\left[\frac{6+7}{2}\right]^{2}+\sum_{u v \in E_{3}}\left[\frac{7+10}{2}\right]^{2}+\sum_{u v \in E_{4}}\left[\frac{8+10}{2}\right]^{2} \\
& +\sum_{u v \in E_{5}}\left[\frac{10+10}{2}\right]^{2} \\
= & 424 b-218 .
\end{aligned}
$$

Case 3: From Table 3, we use the edge partition for $a>1, b=1$ in equation 3 to obtain,

$$
\begin{gathered}
S K 2_{N^{c}}=\sum_{u v \in E_{1}}\left[\frac{6+6}{2}\right]^{2}+\sum_{u v \in E_{2}}\left[\frac{6+7}{2}\right]^{2}+\sum_{u v \in E_{3}}\left[\frac{7+7}{2}\right]^{2}+\sum_{u v \in E_{4}}\left[\frac{7+10}{2}\right]^{2} \\
+\sum_{u v \in E_{5}}\left[\frac{7+11}{2}\right]^{2}+\sum_{u v \in E_{6}}\left[\frac{10+11}{2}\right]^{2}+\sum_{u v \in E_{7}}\left[\frac{11+11}{2}\right]^{2} \\
=\frac{906 \mathrm{a}-553}{2} .
\end{gathered}
$$

Case 4: From Table 4, we use the edge partition for $\mathrm{a}=1, \mathrm{~b}=1$ in equation 3 to obtain,

$$
S K 2_{N^{c}}=\sum_{u v \in E_{1}}\left[\frac{6+6}{2}\right]^{2}=\mathbf{2 1 6} .
$$

Theorem 3.4: $m R_{N^{c}}$ index of Graphene with a rows and $b$ benzene rings is given by 


$$
m R_{N^{c}}=\left\{\begin{array}{lll}
\frac{1150 a+1078 b+1155 a b-1505}{4620} & \text { if } & a>1, b>1 \\
\frac{21 b+17}{42} & \text { if } & a=1, b>1 \\
13\left[\frac{45 a+34}{1155}\right] & \text { if } & a>1, b=1 \\
1 & \text { if } & a=1, b=1
\end{array}\right.
$$

Proof: We provide the proof for the four cases,

Case 1: From Table 1, we use the edge partition for $a>1, b>1$ in equation 4 to obtain,

$$
\begin{aligned}
& m R_{N^{c}}=\sum_{u v \in E_{1}}\left[\frac{1}{\max \{6,7\}}\right]+\sum_{u v \in E_{2}}\left[\frac{1}{\max \{7,7\}}\right]+\sum_{u v \in E_{3}}\left[\frac{1}{\max \{7,10\}}\right]+\sum_{u v \in E_{4}}\left[\frac{1}{\max \{7,11\}}\right] \\
& +\sum_{u v \in E_{5}}\left[\frac{1}{\max \{8,10\}}\right]+\sum_{u v \in E_{6}}\left[\frac{1}{\max \{10,12\}}\right]+\sum_{u v \in E_{7}}\left[\frac{1}{\max \{11,11\}}\right] \\
& +\sum_{u v \in E_{8}}\left[\frac{1}{\max \{11,12\}}\right]+\sum_{u v \in E_{9}}\left[\frac{1}{\max \{12,12\}}\right] \\
& =\frac{1150 a+1078 b+1155 a b-1505}{4620} \text {. }
\end{aligned}
$$

Case 2: From Table 2, we use the edge partition for $a=1, b>1$ in equation 4 to obtain,

$$
\begin{gathered}
m R_{N^{c}}=\sum_{u v \in E_{1}}\left[\frac{1}{\max \{6,6\}}\right]+\sum_{u v \in E_{2}}\left[\frac{1}{\max \{6,7\}}\right]+\sum_{u v \in E_{3}}\left[\frac{1}{\max \{7,10\}}\right]+\sum_{u v \in E_{4}}\left[\frac{1}{\max \{8,10\}}\right] \\
+\sum_{u v \in E_{5}}\left[\frac{1}{\max \{10,10\}}\right] \\
=\frac{21 b+17}{42} .
\end{gathered}
$$

Case 3: From Table 3, we use the edge partition for $\mathrm{a}>1, \mathrm{~b}=1$ in equation 4 to obtain,

$$
\begin{gathered}
m R_{N^{c}}=\sum_{u v \in E_{1}}\left[\frac{1}{\max \{6,6\}}\right]+\sum_{u v \in E_{2}}\left[\frac{1}{\max \{6,7\}}\right]+\sum_{u v \in E_{3}}\left[\frac{1}{\max \{7,7\}}\right]+\sum_{u v \in E_{4}}\left[\frac{1}{\max \{7,10\}}\right] \\
+\sum_{u v \in E_{5}}\left[\frac{1}{\max \{7,11\}}\right]+\sum_{u v \in E_{6}}\left[\frac{1}{\max \{10,11\}}\right]+\sum_{u v \in E_{7}}\left[\frac{1}{\max \{11,11\}}\right] \\
=13\left[\frac{45 a+34}{1155}\right] .
\end{gathered}
$$

Case 4: From Table 4, we use the edge partition for $\mathrm{a}=1, \mathrm{~b}=1$ in equation 4 to obtain,

$$
m R_{N^{c}}=\sum_{u v \in E_{1}}\left[\frac{1}{\max \{6,6\}}\right]=1
$$

Theorem 3.5: $I S I_{N^{c}}$ index of Graphene structure with a rows and $b$ benzene rings is given by 


$$
I S I_{N^{c}}=\left\{\begin{array}{lll}
\frac{2533102 a+2358512 b+9057906 a b-5414079}{503217} & \text { if } & a>1, b>1 \\
\frac{45305 b-10267}{1989} & \text { if } & a=1, b>1 \\
\frac{642005 a-159871}{27846} & \text { if } & a>1, b=1 \\
18 & \text { if } & a=1, b=1
\end{array}\right.
$$

Proof: We provide the proof for the four cases,

Case 1: From Table 1, we use the edge partition for $\mathrm{a}>1, \mathrm{~b}>1$ in equation 5 to obtain,

$$
\begin{gathered}
I S I_{N^{c}}=\sum_{u v \in E_{1}}\left[\frac{(6 * 7)}{(6+7)}\right]+\sum_{u v \in E_{2}}\left[\frac{(7 * 7)}{(7+7)}\right]+\sum_{u v \in E_{3}}\left[\frac{(7 * 10)}{(7+10)}\right]+\sum_{u v \in E_{4}}\left[\frac{(7 * 11)}{(7+11)}\right]+ \\
\sum_{u v \in E_{5}}\left[\frac{(8 * 10)}{(8+10)}\right]+\sum_{u v \in E_{6}}\left[\frac{(10 * 12)}{(10+12)}\right]+\sum_{u v \in E_{7}}\left[\frac{(11 * 11)}{(11+11)}\right]+\sum_{u v \in E_{8}}\left[\frac{(11 * 12)}{(11+12)}\right]+\sum_{u v \in E_{9}}\left[\frac{(12 * 12)}{(12+12)}\right] \\
=\frac{2533102 a+2358512 b+9057906 a b-5414079}{503217} .
\end{gathered}
$$

Case 2: From Table 2, we use the edge partition for $\mathrm{a}=1, \mathrm{~b}>1$ in equation 5 to obtain,

$$
\begin{gathered}
I S I_{N^{c}}=\sum_{u v \in E_{1}}\left[\frac{(6 * 6)}{(6+6)}\right]+\sum_{u v \in E_{2}}\left[\frac{(6 * 7)}{(6+7)}\right]+\sum_{u v \in E_{3}}\left[\frac{(7 * 10)}{(7+10)}\right]+\sum_{u v \in E_{4}}\left[\frac{(8 * 10)}{(8+10)}\right]+ \\
\sum_{u v \in E_{6}}\left[\frac{(10 * 10)}{(10+10)}\right] \\
=\frac{45305 b-10267}{1989} .
\end{gathered}
$$

Case 3: From Table 3, we use the edge partition for $\mathrm{a}>1, \mathrm{~b}=1$ in equation 5 to obtain,

$$
\begin{aligned}
& I S I_{N^{c}}=\sum_{u v \in E_{1}}\left[\frac{(6 * 6)}{(6+6)}\right]+\sum_{u v \in E_{2}}\left[\frac{(6 * 7)}{(6+7)}\right]+\sum_{u v \in E_{3}}\left[\frac{(7 * 7)}{(7+7)}\right]+\sum_{u v \in E_{4}}\left[\frac{(7 * 10)}{(7+10)}\right]+ \\
& \sum_{u v \in E_{5}}\left[\frac{(7 * 11)}{(7+11)}\right]+\sum_{u v \in E_{6}}\left[\frac{(10 * 11)}{(10+11)}\right]+\sum_{u v \in E_{7}}\left[\frac{(11 * 11)}{(11+11)}\right] \\
& =\frac{642005 a-159871}{27846} \text {. }
\end{aligned}
$$

Case 4: From Table 4, we use the edge partition for $\mathrm{a}=1, \mathrm{~b}=1$ in equation 5 to obtain,

$$
I S I_{N^{c}}=\sum_{u v \in E_{1}}\left[\frac{(6 * 6)}{(6+6)}\right]=18 .
$$

\section{Results on Reciprocal Closed Neighborhood Degree}

In this section, we compute the reciprocal closed neighborhood degree-based topological indices, namely $R S K_{N}^{c}, R S K 1_{N}^{c}, R S K 2_{N}^{c}, R m R_{N}^{c}, R I S I_{N}^{c}$ of Graphene structures.

Theorem 4.1: $R S K_{N^{c}}$ index of Graphene with a rows and $b$ benzene rings is given by 


$$
R S K_{N^{c}}=\left\{\begin{array}{lll}
\frac{4178668 a+4127396 b+3522519 a b+1553433}{14090076} & \text { if } & a>1, b>1 \\
\frac{8\left[\frac{1547 b+1223}{19890}\right]}{15359+65102} & \text { if } & a=1, b>1 \\
1 & \text { if } & a>1, b=1
\end{array}\right.
$$

Proof: We provide the proof for the four cases,

Case 1: From Table 1, we use the edge partition for $\mathrm{a}>1, \mathrm{~b}>1$ in equation 6 to obtain,

$$
\begin{aligned}
& R S K_{N} c=\sum_{u v \in E_{1}}\left[\frac{2}{6+7}\right]+\sum_{u v \in E_{2}}\left[\frac{2}{7+7}\right]+\sum_{u v \in E_{3}}\left[\frac{2}{7+10}\right]+\sum_{u v \in E_{4}}\left[\frac{2}{7+11}\right]+ \\
& \sum_{u v \in E_{5}}\left[\frac{2}{8+10}\right]+\sum_{u v \in E_{6}}\left[\frac{2}{10+12}\right]+\sum_{u v \in E_{7}}\left[\frac{2}{11+11}\right]+\sum_{u v \in E_{8}}\left[\frac{2}{11+12}\right]+\sum_{u v \in E_{9}}\left[\frac{2}{12+12}\right] \\
&=\frac{4178668 a+4127396 b+3522519 a b+1553433}{14090076} .
\end{aligned}
$$

Case 2: From Table 2, we use the edge partition for $a=1, b>1$ in equation 6 to obtain,

$$
\begin{aligned}
& R S K_{N^{c}}=\sum_{u v \in E_{1}}\left[\frac{2}{6+6}\right]+\sum_{u v \in E_{2}}\left[\frac{2}{6+7}\right]+\sum_{u v \in E_{3}}\left[\frac{2}{7+10}\right]+\sum_{u v \in E_{4}}\left[\frac{2}{8+10}\right]+ \\
& \sum_{u v \in E_{5}}\left[\frac{2}{10+10}\right] \\
& =7\left[\frac{1547 b+1223}{19890}\right] \text {. }
\end{aligned}
$$

Case 3: From Table 3, we use the edge partition for $a>1, b=1$ in equation 6 to obtain,

$$
\begin{aligned}
R S K_{N} c & =\sum_{u v \in E_{1}}\left[\frac{2}{6+6}\right]+\sum_{u v \in E_{2}}\left[\frac{2}{6+7}\right]+\sum_{u v \in E_{3}}\left[\frac{2}{7+7}\right]+\sum_{u v \in E_{4}}\left[\frac{2}{7+10}\right]+\sum_{u v \in E_{5}}\left[\frac{2}{7+11}\right]+ \\
\sum_{u v \in E_{6}}\left[\frac{2}{10+11}\right]+\sum_{u v \in E_{7}}\left[\frac{2}{11+11}\right] & \\
\quad= & \frac{83759 a+65102}{153153} .
\end{aligned}
$$

Case 4: From Table 4, we use the edge partition for $a=1, b=1$ in equation 6 to obtain,

$$
R S K_{N^{c}}=\sum_{u v \in E_{1}}\left[\frac{2}{6+6}\right]=1 .
$$

Theorem 4.2: $R S K 1_{N^{c}}$ index of Graphene with a rows and b benzene rings is given by

$$
R S K 1_{N^{c}}=\left\{\begin{array}{lll}
2\left[\frac{179380 a+166012 b+88935 a b+194089}{4268880}\right] & \text { if } & a>1, b>1 \\
8\left[\frac{378 b+617}{25200}\right] & \text { if } & a=1, b>1 \\
4\left[\frac{33570 a+49109}{1067220}\right] & \text { if } & a>1, b=1 \\
\frac{1}{3} & \text { if } & a=1, b=1
\end{array}\right.
$$

Proof: We provide the proof for the four cases, 
Case 1: From Table 1, we use the edge partition for $a>1, b>1$ in equation 7 to obtain,

$$
\begin{gathered}
R S K 1_{N^{c}}=\sum_{u v \in E_{1}}\left[\frac{2}{6 * 7}\right]+\sum_{u v \in E_{2}}\left[\frac{2}{7 * 7}\right]+\sum_{u v \in E_{3}}\left[\frac{2}{7 * 10}\right]+\sum_{u v \in E_{4}}\left[\frac{2}{7 * 11}\right]+\sum_{u v \in E_{5}}\left[\frac{2}{8 * 10}\right] \\
+\sum_{u v \in E_{6}}\left[\frac{2}{10 * 12}\right]+\sum_{u v \in E_{7}}\left[\frac{2}{11 * 11}\right]+\sum_{u v \in E_{8}}\left[\frac{2}{11 * 12}\right]+\sum_{u v \in E_{9}}\left[\frac{2}{12 * 12}\right] \\
=2\left[\frac{179380 a+166012 b+88935 a b+194089}{4268880}\right] .
\end{gathered}
$$

Case 2: From Table 2, we use the edge partition for $\mathrm{a}=1, \mathrm{~b}>1$ in equation 7 to obtain,

$$
\begin{gathered}
R S K 1_{N^{c}}=\sum_{u v \in E_{1}}\left[\frac{2}{6 * 6}\right]+\sum_{u v \in E_{2}}\left[\frac{2}{6 * 7}\right]+\sum_{u v \in E_{3}}\left[\frac{2}{7 * 10}\right]+\sum_{u v \in E_{4}}\left[\frac{2}{8 * 10}\right] \\
+\sum_{u v \in E_{5}}\left[\frac{2}{10 * 10}\right] \\
=8\left[\frac{378 \mathrm{~b}+617}{25200}\right] .
\end{gathered}
$$

Case 3: From Table 3, we use the edge partition for $\mathrm{a}>1, \mathrm{~b}=1$ in equation 7 to obtain,

$$
\begin{gathered}
R S K 1_{N^{c}}=\sum_{u v \in E_{1}}\left[\frac{2}{6 * 6}\right]+\sum_{u v \in E_{2}}\left[\frac{2}{6 * 7}\right]+\sum_{u v \in E_{3}}\left[\frac{2}{7 * 7}\right]+\sum_{u v \in E_{4}}\left[\frac{2}{7 * 10}\right]+\sum_{u v \in E_{5}}\left[\frac{2}{7 * 11}\right] \\
+\sum_{u v \in E_{6}}\left[\frac{2}{10 * 11}\right]+\sum_{u v \in E_{7}}\left[\frac{2}{11 * 11}\right] \\
=4\left[\frac{33570 a+49109}{1067220}\right] .
\end{gathered}
$$

Case 4: From Table 4, we use the edge partition for $\mathrm{a}=1, \mathrm{~b}=1$ in equation 7 to obtain,

$$
R S K 1_{N^{c}}=\sum_{u v \in E_{1}}\left[\frac{2}{6 * 6}\right]=\frac{1}{3} .
$$

Theorem 4.3: $R S K 2_{N^{c}}$ index of Graphene with a rows and $b$ benzene rings is given by

$$
R S K 2_{N^{c}}=\left\{\begin{array}{lll}
0.0407 a+0.0381 b+\left(\frac{a b}{48}\right)+0.0452 & \text { if } & a>1, b>1 \\
0.0594 b+0.0968 & \text { if } & a=1, b>1 \\
0.0616 a+0.0922 & \text { if } & a>1, b=1 \\
\frac{1}{6} & \text { if } & a=1, b=1
\end{array}\right.
$$

Proof: We provide the proof for the four cases,

Case 1: From Table 1, we use the edge partition for $\mathrm{a}>1, \mathrm{~b}>1$ in equation 8 to obtain, 


$$
\begin{aligned}
R S K 2_{N}{ }^{c}= & \sum_{u v \in E_{1}}\left[\frac{2}{6+7}\right]^{2}+\sum_{u v \in E_{2}}\left[\frac{2}{7+7}\right]^{2}+\sum_{u v \in E_{3}}\left[\frac{2}{7+10}\right]^{2}+\sum_{u v \in E_{4}}\left[\frac{2}{7+11}\right]^{2} \\
& +\sum_{u v \in E_{5}}\left[\frac{2}{8+10}\right]^{2}+\sum_{u v \in E_{6}}\left[\frac{2}{10+12}\right]^{2}+\sum_{u v \in E_{7}}\left[\frac{2}{11+11}\right]^{2} \\
& +\sum_{u v \in E_{8}}\left[\frac{2}{11+12}\right]^{2}+\sum_{u v \in E_{9}}\left[\frac{2}{12+12}\right]^{2} \\
= & 0.0407 a+0.0381 b+\left(\frac{a b}{48}\right)+0.0452
\end{aligned}
$$

Case 2: From Table 2, we use the edge partition for $\mathrm{a}=1, \mathrm{~b}>1$ in equation 8 to obtain, $R S K 2_{N^{c}}=\sum_{u v \in E_{1}}\left[\frac{2}{6+6}\right]^{2}+\sum_{u v \in E_{2}}\left[\frac{2}{6+7}\right]^{2}+\sum_{u v \in E_{3}}\left[\frac{2}{7+10}\right]^{2}+\sum_{u v \in E_{4}}\left[\frac{2}{8+10}\right]^{2}+$ $\sum_{u v \in E_{5}}\left[\frac{2}{10+10}\right]^{2}$

$$
=0.0594 b+0.0968
$$

Case 3: From Table 3, we use the edge partition for $\mathrm{a}>1, \mathrm{~b}=1$ in equation 8 to obtain,

$$
\begin{gathered}
R S K 2_{N^{c}}=\sum_{u v \in E_{1}}\left[\frac{2}{6+6}\right]^{2}+\sum_{u v \in E_{2}}\left[\frac{2}{6+7}\right]^{2}+\sum_{u v \in E_{3}}\left[\frac{2}{7+7}\right]^{2}+\sum_{u v \in E_{4}}\left[\frac{2}{7+10}\right]^{2} \\
+\sum_{u v \in E_{5}}\left[\frac{2}{7+11}\right]^{2}+\sum_{u v \in E_{6}}\left[\frac{2}{10+11}\right]^{2}+\sum_{u v \in E_{7}}\left[\frac{2}{11+11}\right]^{2} \\
=0.0616 a+0.0922 .
\end{gathered}
$$

Case 4: From Table 4, we use the edge partition for $\mathrm{a}=1, \mathrm{~b}=1$ in equation 8 to obtain,

$$
R S K 2_{N^{c}}=\sum_{u v \in E_{1}}\left[\frac{2}{6+6}\right]^{2}=\frac{1}{6}
$$

Theorem 4.4: $R m R_{N^{c}}$ index of Graphene with a rows and $b$ benzene rings is given by

$$
R m R_{N^{c}}=\left\{\begin{array}{lll}
16 a+16 b+36 a b-26 & \text { if } & a>1, b>1 \\
50 b-10 & \text { if } & a=1, b>1 \\
51 a-11 & \text { if } & a>1, b=1 \\
36 & \text { if } & a=1, b=1
\end{array}\right.
$$

Proof: We provide the proof for the four cases,

Case 1: From Table 1, we use the edge partition for $\mathrm{a}>1, \mathrm{~b}>1$ in equation 9 to obtain,

$$
\begin{aligned}
R m R_{N^{c}}=\sum_{u v \in E_{1}}[\max \{6,7\}]+\sum_{u v \in E_{2}}[\max \{7,7\}]+\sum_{u v \in E_{3}}[\max \{7,10\}] \\
+\sum_{u v \in E_{4}}[\max \{7,11\}]+\sum_{u v \in E_{5}}[\max \{8,10\}]+\sum_{u v \in E_{6}}[\max \{10,12\}] \\
+\sum_{u v \in E_{7}}[\max \{11,11\}]+\sum_{u v \in E_{8}}[\max \{11,12\}]
\end{aligned}
$$




$$
=16 a+16 b+36 a b-26 .
$$

Case 2: From Table 2, we use the edge partition for $a=1, b>1$ in equation 9 to obtain,

$$
\begin{gathered}
R m R_{N^{c}}=\sum_{u v \in E_{1}}[\max \{6,6\}]+\sum_{u v \in E_{2}}[\max \{6,7\}]+\sum_{u v \in E_{3}}[\max \{7,10\}] \\
+\sum_{u v \in E_{4}}[\max \{8,10\}]+\sum_{u v \in E_{5}}[\max \{10,10\}] \\
=50 b-10 .
\end{gathered}
$$

Case 3: From Table 3, we use the edge partition for $\mathrm{a}>1, \mathrm{~b}=1$ in equation 9 to obtain,

$$
\begin{gathered}
R m R_{N^{c}}=\sum_{u v \in E_{1}}[\max \{6,6\}]+\sum_{u v \in E_{2}}[\max \{6,7\}]+\sum_{u v \in E_{3}}[\max \{7,7\}]+\sum_{u v \in E_{4}}[\max \{7,10\}] \\
+\sum_{u v \in E_{5}}[\max \{7,11\}]+\sum_{u v \in E_{6}}[\max \{10,11\}]+\sum_{u v \in E_{7}}[\max \{11,11\}] \\
=51 a-11 .
\end{gathered}
$$

Case 4: From Table 4, we use the edge partition for $\mathrm{a}=1, \mathrm{~b}=1$ in equation 9 to obtain,

$$
R m R_{N^{c}}=\sum_{u v \in E_{1}}\left[\frac{1}{\max \{6,6\}}\right]=36 .
$$

Theorem 4.5: $R I S I_{N^{c}}$ index of Graphene with a rows and $b$ benzene rings is given by

$$
R_{I S I_{N^{c}}}=\left\{\begin{array}{lll}
24\left[\frac{1425 a+1386 b+1155 a b+505}{55440}\right] & \text { if } & a>1, b>1 \\
120\left[\frac{231 b+184}{25200}\right] & \text { if } & a=1, b>1 \\
12\left[\frac{1290 a+973}{13860}\right] & \text { if } & a>1, b=1 \\
2 & \text { if } & a=1, b=1
\end{array}\right.
$$

Proof: We provide the proof for the four cases,

Case 1: From Table 1, we use the edge partition for $a>1, b>1$ in equation 10 to obtain,

$$
\begin{gathered}
\operatorname{RISI}_{N^{c}}=\sum_{u v \in E_{1}}\left[\frac{(6+7)}{(6 * 7)}\right]+\sum_{u v \in E_{2}}\left[\frac{(7+7)}{(7 * 7)}\right]+\sum_{u v \in E_{3}}\left[\frac{(7+10)}{(7 * 10)}\right]+\sum_{u v \in E_{4}}\left[\frac{(7+11)}{(7 * 11)}\right] \\
+\sum_{u v \in E_{5}}\left[\frac{(8+10)}{(8 * 10)}\right]+\sum_{u v \in E_{6}}\left[\frac{(10+12)}{(10 * 12)}\right]+\sum_{u v \in E_{7}}\left[\frac{(11+11)}{(11 * 11)}\right] \\
+\sum_{u v \in E_{8}}\left[\frac{(11+12)}{(11 * 12)}\right]+\sum_{u v \in E_{9}}\left[\frac{(12+12)}{(12 * 12)}\right] \\
=24\left[\frac{1425 a+1386 b+1155 a b+505}{55440}\right] .
\end{gathered}
$$

Case 2: From Table 2, we use the edge partition for $a=1, b>1$ in equation 10 to obtain, 


$$
\begin{gathered}
\operatorname{RISI}_{N^{c}}=\sum_{u v \in E_{1}}\left[\frac{(6+6)}{(6 * 6)}\right]+\sum_{u v \in E_{2}}\left[\frac{(6+7)}{(6 * 7)}\right]+\sum_{u v \in E_{3}}\left[\frac{(7+10)}{(7 * 10)}\right]+\sum_{u v \in E_{4}}\left[\frac{(8+10)}{(8 * 10)}\right] \\
+\sum_{u v \in E_{6}}\left[\frac{(10+10)}{(10 * 10)}\right] \\
=120\left[\frac{231 \mathrm{~b}+184}{25200}\right] .
\end{gathered}
$$

Case 3: From Table 3, we use the edge partition for $\mathrm{a}>1, \mathrm{~b}=1$ in equation 10 to obtain,

$$
\begin{gathered}
R I S I_{N^{c}}=\sum_{u v \in E_{1}}\left[\frac{(6+6)}{(6 * 6)}\right]+\sum_{u v \in E_{2}}\left[\frac{(6+7)}{(6 * 7)}\right]+\sum_{u v \in E_{3}}\left[\frac{(7+7)}{(7 * 7)}\right]+\sum_{u v \in E_{4}}\left[\frac{(7+10)}{(7 * 10)}\right] \\
+\sum_{u v \in E_{5}}\left[\frac{(7+11)}{(7 * 11)}\right]+\sum_{u v \in E_{6}}\left[\frac{(10+11)}{(10 * 11)}\right]+\sum_{u v \in E_{7}}\left[\frac{(11+11)}{(11 * 11)}\right] \\
=12\left[\frac{1290 a+973}{13860}\right] .
\end{gathered}
$$

Case 4: From Table 4, we use the edge partition for $a=1, b=1$ in equation 10 to obtain,

$$
\operatorname{RISI}_{N^{c}}=\sum_{u v \in E_{1}}\left[\frac{(6+6)}{(6 * 6)}\right]=2 .
$$

\section{Conclusions}

The analysis of chemical molecules and the study of how the indices relate to the molecular properties is made possible by computing numerous topological indices of chemical graphs. We determined the cardinality of closed neighborhood degree edge partitions corresponding to four distinct Graphene structures and computed 10 closed neighborhood degree sum-based topological indices. In our future work, we plan to apply these descriptors to various transformations of Graphene structures.

\section{Funding}

This research received no external funding.

\section{Acknowledgments}

We thank the reviewers for their constructive comments in improving the quality of this paper.

\section{Conflicts of Interest}

The authors declare no conflict of interest.

\section{References}

1. Ahmad, M.; Afzal, D.; Nazeer, W.; Kang, S. On topological indices of octagonal network. Far East Journal of Mathematical Sciences 2017, 102, 2563-2571, http://dx.doi.org/10.17654/MS102112563.

2. Aslam, A.; Guirao, J.; Ahmad, S.; Gao, W. Topological Indices of the Line Graph of Subdivision Graph of Complete Bipartite Graphs. Applied Mathematics \& Information Sciences 2017, 11, 1631-1636, http://dx.doi.org/10.18576/amis/110610. 
3. Gutman, I. Degree-Based Topological Indices. Croatica Chemica Acta 2013, 86, 351-361, http://dx.doi.org/10.5562/cca2294.

4. West, D.B. An Introduction To Graph Theory. Prentice hall, Inc. New Jersey 1996.

5. Sedlar, J.; Stevanović, D.; Vasilyev, A. On the inverse sum indeg index. Discrete Applied Mathematics 2015, 184, 202-212, https://doi.org/10.1016/j.dam.2014.11.013.

6. Sridhara, G.; Rajesh Kanna, M.R.; Indumathi, R.S. Computation of Topological Indices of Graphene. Journal of Nanomaterials 2015, 2015, https://doi.org/10.1155/2015/969348.

7. Jagadeesh, R.; Rajesh Kanna, M.R.; Indumathi, R.S. Some results on topological indices of Graphene. Nanomaterials and Nanotechnology 2016, 6, 1-6, https://doi.org/10.1177\%2F1847980416679626.

8. Rachanna, R.K.; Vijayalaxmi, S.; Shigehalli. Computing Some Degree-Based Topological Indices of Graphene. Indonesian Journal of Electrical Engineering and Informatics 2017, 5, 115-161, http://dx.doi.org/10.11591/ijeei.v5i2.258.

9. Akhter, S.; Imran, M.; Gao, W.; Farahani, M. On topological indices of honeycomb networks and Graphene networks [253]. Hacettepe Journal of Mathematics and Statistics 2018, 47, 19-35, https://doi.org/10.15672/HJMS.2017.464.

10. Kwun, Y.; Ahmad, J.; Nazeer, W.; Khalid, W.; Kang, S. Topological Invariants Of Molecular Graph Of Graphene. JP Journal of Geometry and Topology 2018, 21, 95-103, http://dx.doi.org/10.17654/GT021020095.

11. Shigehalli, V.S.; Kanabur, R. Computation of New Degree-Based Topological Indices of Graphene. Journal of Mathematics 2016, 2016, https://doi.org/10.1155/2016/4341919.

12. Mondal, S.; De, N.; Pal, A. Topological properties of Graphene using some novel neighborhood degreebased topological indices. International Journal of Mathematics for Industry 2019, 11, https://dx.doi.org/10.1142/S2661335219500060.

13. Berhe, M.; Wang, C. Computation of certain topological coindices of Graphene sheet and $\mathrm{C} 4 \mathrm{C} 8(\mathrm{~S})$ nanotubes and nanotorus. Applied Mathematics and Nonlinear Sciences 2019, 4, 455-468, https://doi.org/10.2478/AMNS.2019.2.00043.

14. Parashivamurthy, H.L.; Kanna M R, R.; Jagadeesh, R. Some Topological Indices and their Polynomials of Graphene. Oriental Journal Of Chemistry 2019, 35, 1514-1518, http://dx.doi.org/10.13005/ojc/350506.

15. Sudhakara, K.; Guruprasad, P.S.; Sriraj, M.A. Some edge degree based topological indices of Graphene. Proceedings of the Jangjeon Mathematical Society 2020, 23, 253-270, https://doi.org/10.17777/pjms2020.23.2.253.

16. Zhu, Y.; Murali, S.; Cai, W.; Li, X.; Suk, J.W.; Potts, J.R.; Ruoff, R.S. Graphene and Graphene Oxide: Synthesis, Properties, and Applications. Advanced Materials 2010, 22, 3906-3924, https://doi.org/10.1002/adma.201001068.

17. Huang, X.; Qi, X.; Boey, F.; Zhang, H. Graphene-based composites. Chemical Society Reviews 2012, 41, 666-686, https://doi.org/10.1039/c1cs15078b.

18. Liu, D.-X.; Li, X.-F.; Zhang, X.-H.; Cao, X.; Zhu, X.-J.; Shi, D. Interface Magnetism in Topological Armchair/Cove-Edged Graphene Nanoribbons. The Journal of Physical Chemistry C 2020, 124, 1544815453, https://doi.org/10.1021/acs.jpcc.0c04152.

19. Rada, J. Vertex-Degree Based Topological Indices of Graphene. Polycyclic Aromatic Compounds 2020, 19, https://doi.org/10.1080/10406638.2020.1785897.

20. Kwun, Y.C.; Virk, A.U.R.; Rafaqat, M.; Rehman, M.U.; Nazeer, W. Some reversed degree-based topological indices for Graphene. Journal of Discrete Mathematical Sciences and Cryptography 2019, 22, 1305-1314, https://doi.org/10.1080/09720529.2019.1691329.

21. Ahmad, A. Computation of certain topological properties of para-line graph of honeycomb networks and Graphene. Discrete Mathematics, Algorithms and Applications 2017, 09, https://doi.org/10.1142/S1793830917500641.

22. Arockiaraj, M.; Clement, J.; Tratnik, N.; Mushtaq, S.; Balasubramanian, K. Weighted Mostar indices as measures of molecular peripheral shapes with applications to Graphene, graphyne and graphdiyne nanoribbons. SAR and QSAR in Environmental Research 2020, 31, 187-208, https://doi.org/10.1080/1062936X.2019.1708459.

23. Putz, M.V.; Ori, O. Topological Symmetry Transition between Toroidal and Klein Bottle Graphenic Systems. Symmetry 2020, 12, https://doi.org/10.3390/sym12081233. 
24. Anwar Saleh.; Sophia Shalini, G. B.; Dhananjayamurthy, B. V. The Reduced Neighborhood Topological Indices and RNM - Polynomial for the Treatment of COVID-19. Biointerface Research in Applied Chemistry 2021, 11, 11817 - 11832, https://doi.org/10.33263/BRIAC114.1181711832.

25. Mondal, S.; De, N.; Siddiqui, M. K..; Pal, A. Topological Properties of Para-Line Graph of Some Convex Polytopes Using Neighborhood M-Polynomial. Biointerface Research in Applied Chemistry 2021, 11, 9915 - 9927, https://doi.org/10.33263/BRIAC113.99159927.

26. Mondal, S.; De, N.; Pal, A. On some new neighbourhood degree based indices. Acta Chemica Iasi 2019, 27 , 31-46, https://doi.org/10.2478/achi-2019-0003.

27. Mondal, S.; De, N.; Pal, A. QSPR analysis of some novel neighborhood degree based topological descriptors, Complex \& Intelligent Systems 2021, 7, 977-966, https://doi.org/10.1007/s40747-020-00262-0.

28. Mondal, S.; De, N.; Pal, A. Neighborhood degree sum-based molecular descriptors of fractal and Cayley tree dendrimers. The European Physical Journal Plus 2021, 136, 1-37, https://doi.org/10.1140/epjp/s13360021-01292-4.

29. Shanmukha, M.C.; Basavarajappa, N.S.; Usha, A.; Shilpa, K.C. Novel neighbourhood redefined first and second Zagreb indices on carborundum structures. Journal of Applied Mathematics and Computing 2021, 66, 263-276, https://doi.org/10.1007/s12190-020-01435-3.

30. Mondal, S.; De, N.; Pal, A. Topological properties of Graphene using some novel neighborhood degreebased topological indices. Int. J. Ind. Math. 2020, 11, https://doi.org/10.1142/S2661335219500060.

31. Mondal, S.; De, N.; Pal, A. On Neighbourhood Zagreb index of product graphs. J. Mol. Struct. 2021, 1223,129210, https://doi.org/10.1016/j.molstruc.2020.129210.

32. Shanmukha, M.C.; Usha, A.; Basavarajappa, N.S; Shilpa, K.C. Graph entropies of porous Graphene using topological indices. Computational and Theoretical Chemistry 2021, 1197, 113142, https://doi.org/10.1016/j.comptc.2021.113142.

33. Mondal, S.; Siddiqui, M.K.; De, N.;Pal, A. Neighborhood M-polynomial of crystallographic structures. Biointerface Res. Appl. Chem. 2021, 11, 9372-9381, https://doi.org/10.33263/BRIAC112.93729381.

34. Sarkar, P.; Pal, A. General Fifth M-Zagreb Polynomials of Benzene Ring Implanted in the P-Type-Surface in 2D Network, Biointerface Res. Appl. Chem. 2020, 10, 6881-6892, https://doi.org/10.33263/BRIAC106.68816892.

35. Ravi, V.; Desikan, K. Neighbourhood Degree-Based Topological Indices of Graphene Structure. Biointerface Research in Applied Chemistry 2021, $11, \quad 13681 \quad$ - 13694, https://doi.org/10.33263/BRIAC115.1368113694.

36. Ravi, V.; Grace, G. H.; Desikan, K.; Venkat, I. Curvilinear Regression Analysis of Some Open Neighbourhood Degree Based Topological Indices with Physico - Chemical Properties of Octane Isomers 2021, (Under Review).

37. Ravi, V.; Desikan, K. Curvilinear Regression Analysis of Some Closed Neighbourhood Degree Based Topological Indices with Physico - Chemical Properties of Octane Isomers 2021, (Under Review). 